\title{
An Audit of Paediatrics Admissions and Outcomes into a General Intensive Care Unit at a Tertiary Teaching Hospital: A Five-Year Review
}

\author{
Adamu S. Abubakar ${ }^{1 *}$, Yauba M. Saad ${ }^{2}$, Hamma G. Ahmed ${ }^{3}$, Wabada $S^{4}$ and Jika Mohammed ${ }^{5}$ \\ ${ }^{1}$ Department of Anaesthesia and Intensive Care, University of Maiduguri Teaching Hospital, Maiduguri, Nigeria \\ ${ }^{2}$ Department of Paediatrics, University of Maiduguri Teaching Hospital, Maiduguri, Nigeria \\ ${ }^{3}$ Department of Internal Medicine, University of Maiduguri Teaching Hospital, Maiduguri, Nigeria \\ ${ }^{4}$ Department of Surgery, University of Maiduguri Teaching Hospital, Maiduguri, Nigeria \\ ${ }^{5}$ Department of Anaesthesia, Federal Teaching Hospital, Gombe. Nigeria
}

\begin{abstract}
Received: 19 July, 2017; Accepted: 29 August, 2017; Published: 22 September, 2017
*Corresponding author: Dr. Adamu Sadiq Abubakar, Department of Anaesthesia, University of Maiduguri Teaching Hospital, P.M.B 1414, Maiduguri, Borno State, Nigeria, GSM: +2348033702600; Email: adamusadiq48@.gmail.com
\end{abstract}

\begin{abstract}
Background: We aimed at auditing the admissions and outcomes of paediatric patients admitted into a general open Intensive Care Unit (ICU).

Patients and Methods: This was a retrospective, case-control study of all paediatric patients (a day old to 17 years old) admitted into our general open ICU of the University of Maiduguri Teaching Hospital, Maiduguri, Borno state, Nigeria. The study was conducted over fiveyear period from January 2012 to December 2016. Patients admitted within the above period were identified through their case notes and the ICU records books and all eligible patients were identified and recruited into the study.
\end{abstract}

Results: A total of 2,565 patients were admitted to the ICU during the study period out of which $508(19.8 \%)$ were children. There were $284(55.9 \%)$ males and 224 (44.1\%) females' paediatric patients with M: F ratio of 1.3: 1 within the period under review. The age ranges between one day old to seventeen years old children with mean age of $3.23 \pm 4.45$ years. Surgical indications for admission into the ICU were the highest with $69.5 \%$, while medical indications were $30.5 \%$. Length of Stay (LOS) in ICU from < 1 day to 90 days with the mean of LOS is $6.02 \pm 23.23$ days. The mortality rate was $26.2 \%$.

Conclusions: The high mortality rates recorded in this study indicate the need to establish paediatric ICU and the urgent need for training and re-training of staff toward new guidelines in the management paediatric patients in ICU.

Key words: Paediatrics Admissions; Outcomes; General ICU;

\section{Introduction}

The Intensive Care Unit (ICU) is a specialized unit in the hospital where critically ill-patients were managed [1]. ICU has been defined as "a service for patients with potentially recoverable diseases who can benefit from more detailed observation and treatment than is generally available in the standard wards and departments" [2]. The British Medical Association (BMA) recommended that $1-2 \%$ of acute hospital beds should be designated for intensive care of patients.

The intensive care unit results were assessed almost exclusively on the basis of the outcomes which is either "death" or "survival" by means of indicators such as mortality rates, readmissions rate, other rates of complications related to certain treatments. Indicators of morbidity are important aids, but can be difficult to quantify, particularly in paediatric patients $[3,4]$.

Globally, there is a shift in the management of paediatric patients from the general ICU to a more special and specific Paediatric ICU (PICU). There were multiple of studies that shows an improvement in outcome of critically ill children managed in the PICU [5-7].

In our centre therefore, we have both general and neonatal ICUs were all critically ill patients were managed. However, going with the global best practice, efforts are been made to establish the PICU and therefore the need to evaluate the practice of the management of paediatric patients in our general ICU. This will form as the baseline and also as a source of comparison in future between those patients that were managed in general ICU and the PICU.

In this study therefore, we aimed at auditing the admissions and outcomes of the management of paediatric patients in our general open ICU.

\section{Materials and Method}

This was a retrospective case-control study of all paediatric patients (a day old to 16 years old) admitted into our general open ICU of the University of Maiduguri Teaching Hospital, Maiduguri, 
Borno state, Nigeria. The study was carried out over a five-year period from; January 2012 to December 2016. The ICU is a sevenbedded unit, where all critically ill patients were admitted from various parts of the hospital through the routine written consults from the paediatric, paediatric surgery, ENT, MFU, Orthopaedic departments among others.

Patients admitted within the above period were identified through their case notes and the ICU records books, all eligible patients were identified and recruited into the study.

The protocol for the study was approved by the Ethical committee of our hospital and no patient's intervention was involved. Each patient's record was reviewed in detail and data retrieved for analysis included the age, gender, diagnosis at admissions, indications for ICU admissions, length of stay in ICU, interventions and outcome of management. Data were presented in rates and percentages. Statistical analysis was performed using Epi- info ${ }^{\mathrm{TM}}$ 7. The association between clinical variables and outcomes were tested using Chi square test. The level of significance was set at a $\mathrm{P} \leq 0.05$.

\section{Results}

A total of 2,565 patients were admitted to the ICU during the study period out of which $508(19.8 \%)$ were children. There were $284(55.9 \%)$ male and $224(44.1 \%)$ female paediatric patients with M: F ratio of 1.3: 1 within the period under review. The ages of the children studied ranges between one day old and seventeen years old with mean age of $3.23 \pm 4.45$ years. The demographic characteristic of the patients (age and genders distribution) are shown in table I. The peak ages occur more in the ages between $>6$ months to 5 years; $p<0.01$ with statically significant differences in the age distribution among the study population. Surgical indications for admission into the ICU were the highest with $69.5 \%$, while medical indications were $30.5 \%$; $\mathrm{p}=0.012$. See table II.

In table III it shows the breakdown of the surgical and medical indications for ICU admissions and the outcomes of management of the patients.

Length of Stay (LOS) in ICU from $<1$ day to 90 days with the mean of LOS is $6.02 \pm 23.23$ days.

Table 1: Age and genders distribution of patients

\begin{tabular}{|l|c|c|c|c|}
\hline Ages (yrs) & Males & Females & Total & (\%) \\
\hline$<1 \mathrm{MTH}$ & 24 & 24 & 48 & 9.5 \\
\hline$>1-6 \mathrm{MTH}$ & 48 & 25 & 73 & 14.4 \\
\hline$>6$ MTH-1YR & 64 & 32 & 96 & 18.9 \\
\hline$>1-5 Y R$ & 64 & 80 & 144 & 28.4 \\
\hline$>5-12$ YR & 34 & 26 & 60 & 11.8 \\
\hline$>12-17$ YR & 50 & 37 & 87 & 17.1 \\
\hline Total & $\mathbf{2 8 4 ( 5 5 . 9 1 \% )}$ & $\mathbf{2 2 4 ( 4 4 . 0 9 \% )}$ & $\mathbf{5 0 8}$ & $\mathbf{1 0 0}$ \\
\hline
\end{tabular}

2: Indications to ICU Admission based on gender among the children admitted in to the ICU

\begin{tabular}{|l|l|l|l|l|}
\hline Specialties & Males & Females & Total & (\%) \\
\hline Medical n(\%) & 104 & 51 & 155 & 30.5 \\
\hline Surgical n(\%) & 228 & 125 & 353 & 69.5 \\
\hline Total & $\mathbf{3 3 2 ( 6 5 . 4 \% )}$ & $\mathbf{1 7 6 ( 3 4 . 6 \% )}$ & $\mathbf{5 0 8 ( 1 0 0 \% )}$ & $\mathbf{1 0 0}$ \\
\hline
\end{tabular}

\section{Discussions}

This study shows that $19.8 \%$ of the patients admitted into our ICU were of the paediatric age groups during the period of this study. This concur with the result obtained by Kushimo et al, [8] where they reported the prevalence of $28.0 \%$ in Lagos, Nigeria, while Embu et al, [9] reported a prevalence of $22.1 \%$ in Jos, Nigeria. However, in variance to the above results Mc Hugh et al, [10] reported lower admission rates of 7.4\% in New Zealand. These low rates may not be unconnected to the fact that in New Zealand there were regionalization of the ICU and equally there were improved means of referral and transportation of patients from one to more specialized centers.

In our study, we observed that from the ages of 6 months to five years of age they were more in number in terms of rate of admissions. The ages of 1-5 years had the highest rates of admission into our ICU with $28.4 \%$ and this may be related to the fact that at that age these patients presented more for surgery as postoperative patients and trauma patients constituted the highest rates of paediatric admission of $64.5 \%$. This was similar to the findings reported by Isamade et al, [11] in Jos, Nigeria where they reported that $74 \%$ of their ICU admission was due to postoperative patients and trauma. Similarly, Embu et al, [9] and Kushimo et al, [8] reported $82 \%$ and $57 \%$ of the patients were due to postoperative and trauma patients respectively. Our high rate of admission of postoperative and trauma patients may be connected to the increase in the surge of the dreaded Boko Haram activities in Maiduguri and its environment, inflicting trauma to the people through suicide bombing and attacked with guns among other terror activities.

The finding of more surgical patients, $69.5 \%$, as compared to medical, $30.5 \%$, ICU admissions in our study may be due to the high rate of postoperative and trauma patients that were admitted into our ICU. This finding was similar to the earlier study conducted in the same centre among adult patients by Adamu et al, [12] where they reported ICU admission as high as $17.9 \%$ for same documented reason. However, this defers to the findings of Embu et al, [9] where they found the highest number of admissions was among the neonatal age group and the reason proffer was that there was absence of neonatal ICU in their centre. However, they also reported significantly high admission rates in the ages of 3-15 years the reason stated was similar to our observation that the age group were highly vulnerable to trauma.

In our study, we observed the Length of Stay (LOS) in ICU varies from $<1$ day to 90 days $(6.02 \pm 23.23)$ days. The length of 
stay in ICU has been sounded to a good reflection of the severity of the patient's illness and the health status of the patients as well as the quality and performance. Previous studies, also agreed that there is a direct correlation between the length of stay and the outcome of paediatric patients as was observed in this study [1315]. However, El Nawawy, stated otherwise that greater mortality in paediatric patients was associated with shorter LOS [16].

We observed that various interventions were carried out in the course of management of these children in our ICU. These include among other interventions were Arterial line insertion, Mechanical ventilation and central venous catheterization were commonest interventions carried out in the ICU and interventions invariably results in the high survival rate seen this study.

We observed the survival rates of $73.77 \%$ this was similar to the study by Adamu et al, [12] in adult patients, where they reported the survival rate of $78.9 \%$ in adult patients admitted into the ICU.

The mortality rate of $26.2 \%$ documented among paediatric patients in our ICU admissions was similar to previous studies elsewhere $[8,9,11]$. However, others reported lower rate of $7.4 \%$ as a low-moderate risk [17]. However, in this study it is not easy to ascertain the level of risk as this study is a retrospective in nature and no such data in the record book that was used in this study.

\section{Conclusion}

The high rate of admission of paediatric patients in this study with proportional higher mortality rates recorded precludes the needs to establish paediatric ICU and the urgent need for training and re-training of staff toward new guidelines in the management of paediatric patients in ICU. Similarly, this is to recommend the establishment of PICU in all tertiary health institutions in Nigeria in particular and the developing countries in general.

\begin{tabular}{|c|c|c|c|c|}
\hline Indications & Number (\%) & Survival (\%) & Dead (\%) & P-value \\
\hline Surgical & $353(69.5)$ & $284(80.5)$ & $69(19.6)$ & $<0.01$ \\
\hline Polytraumatized during to bomb blast & $46(13.0)$ & $28(60.9)$ & $18(39.1)$ & \\
\hline Head injury & $36(10.2)$ & $22(61.1)$ & $14(38.9)$ & \\
\hline Burns & $32(9.1)$ & $18(56.3)$ & $14(43.8)$ & \\
\hline Postoperative & $239(67.7)$ & 195(81.6) & $44(18.4)$ & $<0.01$ \\
\hline Paediatrics surgery & $38(15.9)$ & $29(76.3)$ & 09 (23.7) & \\
\hline ENT & $28(11.7)$ & $25(89.3)$ & $03(10.7)$ & \\
\hline Orthopaedic & $14(5.9)$ & $14(100)$ & Nil & \\
\hline MFU & $37(15.5)$ & $35(94.6)$ & $2(5.4)$ & \\
\hline Obstetrics & $44(18.4)$ & 37 (84.1) & $7(15.9)$ & $<0.01$ \\
\hline Gynaecology & $28(11.7)$ & $26(92.9)$ & $2(7.1)$ & \\
\hline Neurosurgery & $12(5.0)$ & $11(91.7)$ & $1(8.3)$ & \\
\hline Others & $38(15.9)$ & $34(89.5)$ & $4(10.5)$ & \\
\hline Medical & $155(30.5)$ & $134(85.2)$ & $11(13.6)$ & $<0.01$ \\
\hline Severe meningitis & $28(18.1)$ & 25 (89.3) & $3(10.7)$ & \\
\hline Septicaemia & $24(15.5)$ & $21(87.5)$ & $3(12.5)$ & \\
\hline Severe Asthma & $14(9.0)$ & $12(85.7)$ & $2(14.3)$ & \\
\hline Severe Tetanus & $2(14.3)$ & $20(95.2)$ & $1(4.8)$ & \\
\hline Congenital heart diseases & $14(9.0)$ & Referred & & \\
\hline Respiratory failure & $22(14.2)$ & $21(95.5)$ & $1(4.6)$ & \\
\hline Others & $32(20.7)$ & 31 (96.9) & $1(3.1)$ & \\
\hline Total Mortality & & & $80(26.2)$ & \\
\hline
\end{tabular}




\section{Reference}

1. Grenvik A, Leonard JJ, Arens JR. Crtical Care Medicine Certification as a Multi-Displinary Sub-Specialty. Crit Care Med. 1981;9(2):117-125.

2. Morrison AL, Gillis J, O'Connell AJ, Schell DN, Dossetor DR, Mellis C. Quality of life of survivors of pediatric intensive care. Pediatr Crit Care Med. 2002;3(1):1-5.

3. Fiser DH. Assessing the Outcome of Paediatric Intensive Care. J Pediatr 1992;121:68-74.

4. Odetola FO, Rosenberg AL, Davies MM, Clarke SJ, Dechart RE, Shanley TP. Do Outcomes Vary According To The Source Of Admission To Paediatric Intensive Care Unit? PediatrCrit Care Med. 2008;9:20-25 2008;9(1):20-25. doi: 10.1097/01.PCC.0000298642.11872.29

5. Pollack MM, Alexander SR, Clarke N, Ruttimann UE, Tesselaar HM, Bachulis AC. Improved Outcomes From Tertiary Centre Pediatric Intensive Care. A State Wide Comparison of Tertiary and Non-Tertiary Centres. A national Multi-Centre Study. Crit Care Med. 1991;19(2):150159.

6. Gemke RJ, Bonsel GJ. The Paediatric Intensive Care Assessment of Outcome Study Group. (PICASSO). Comparative Assessment of Pediatric Intensive Care. A national multicentre Study. Crit Care Med. 1995;23(2):238-345.

7. Henderson AJ, Garland L, Warne S, Bailey L, Weir P, Edees S. Risk Adjusted Mortality Critically Illness In A Defined Geographical Region. Arch Dis Childhood. 2002;86(3):194-199.

8. Kushimo OT, Okeke CI, Ffoulkes- Crabbes DJ. Paediatric Admission into the Intensive Care Unit of Lagos University Teaching Hospital. Nig Hosp J Med. 1988;8:52-55.
9. Embu HY, Yiltok SJ, Isamade ES, Nuhu SI, Oyeniron 00, Uba FA. Paediatric Admissions and Outcomes in a General Intensive Care. Afri J Paediatr Surg. 2011;8(1):57-61. doi: 10.4103/0189-6725.78670

10. McHugh GJ, Hicks PR. Paediatric Admissions to the General Intensive Care Unit at Palmerstorn North Hospital. Crit Care Resusc. 1999;1(3):234-238.

11. Isamade ES, Yiltoksj, Uba AF, Isamade EI, Daru PH. Intensive Care Unit Admissions In A University Teaching Hospital. Nig J Clin Practice. 2007;10(2):156-161.

12. Adamu SA, Abubakar AB, Tela UM, Deba BU, Ngamdu YB, Yusuf ST. Admissions and Outcomes of Intensive Care Management of Severely Head Injured Patients in Non-Surgical Centre. Journal of Anesthesiology. 2014;2(2):18-21.

13. Oyegunle AO, Oyegunle VA. The Intensive Care Unit in a Young Nigerian Teaching Hospital: The Sagamu (1994-1997) ExperienceAretrospective Study. Afr J Anaesth Int Care. 1997;3:41-43.

14. Olabanji JK, Oginni FO, Bankole JO, OlasindeAA. A Ten-Year Review of Burn Cases Seen in a Nigerian Teaching Hospital. J Burns Surg Wound Care. 2002;1:1-9.

15. F foulkes-Crabbe DJ. The Intensive Care Unit of the Lagos University Teaching Hospital - An Anaesthetist' Experience Of Great Britain and Ireland. United Kingdom. 1998;7:5-7.

16. El-Nawawy A. Evaluation of The Outcome Of Patient's Admitted To The Pediatric Intensive Care Unit In Alexandria Using The Pediatric Risk Mortality Score. J Trop Pediatr. 2003;49:109-114.

17.Zimmerman JE, Wagner DP, Knaus WA, Williams JF, Kolakowski D, Draper EA. The Use of Risk Predictors to Identify Candidates for Intermediate Care Units; Implications for Intensive Care Utilization and Cost. Chest. 1995;108(2):490-499. 